\title{
2861. The development of a dynamic fracture propagation model for FRP-strengthened beam-column joints
}

\author{
Shahriar Shahbazpanahi \\ Department of Civil Engineering, Sanandaj Branch, Islamic Azad University, Sanandaj, Iran \\ E-mail: sh.shahbazpanahi@iausdj.ac.ir \\ Received 29 May 2017; received in revised form 20 October 2017; accepted 2 November 2017 \\ DOI https://doi.org/10.21595/jve.2017.18686 \\ Check for updates \\ Copyright (C) 2018 Shahriar Shahbazpanahi. This is an open access article distributed under the Creative Commons Attribution License, \\ which permits unrestricted use, distribution, and reproduction in any medium, provided the original work is properly cited.
}

\begin{abstract}
Accurate modeling is required to investigate the behavior of concrete structures strengthened by carbon fiber-reinforced polymer (CFRP). There is, however, limited knowledge on the use of dynamic modeling to study the crack propagation in the beam-column joints strengthened by CFRP. A finite element model is developed to study crack propagation in the CFRP-strengthened joints under dynamic loads. A three-dimensional model is developed to predict the crack propagation under cyclic loading in the ABAQUS software. In this study, dynamic fracture analysis is used to model the crack propagation in the concrete material. Furthermore, the model is used to predict dynamic debonding in CFRP strengthened with the fracture mechanics approach. The results of the present study showed a good agreement with previous experimental results by about 7.1-11.6\%. The proposed model indicates that the crack propagation is controlled by using CFRP composites in the beam-column joint. Furthermore, it is observed that the width of strut zone in the joint increases by the using of FRP strengthening.
\end{abstract}

Keywords: fracture mechanics, beam-column joint, dynamic, CFRP.

\section{Introduction}

One of the most vulnerable structural elements to sudden failure is the beam-column joint for which the crack propagation behaviour needs to be predicted [1,2]. Cracks in the joint start where the beam and column intersect because of stress increase [3]. The fracture mechanics theory is the best method for predicting this type of crack $[4,5]$.

Beam-column joints, which provide the continuity of a structure, are critical and significant parts of concrete structures [6]. Furthermore, basically the shear force in the joint area has to rely on a compression strut zone. The diagonal compression strut zone is made by the diagonal concrete compression force in the joint area. The increased force along the strut zone may cause failure. Therefore, the study of their behaviour, crack patterns, strut zone, failure mode, and strengthening is essential. Presenting an accurate fracture mechanics model for beam column joints is of great importance owing to the complex behaviour of the joints [7].

The strengthening of joints can be carried out using jacketing steel, bolted steel, or plate steel or by stitching and drilling with grout. Corrosion, confinement, and cost are reasons why these techniques are rarely used. Nowadays, to retrofit a beam column joint, external fiber-reinforced polymer (FRP) is used [8]. However, use of fracture mechanics modelling to analyse dynamic crack propagation in the joints strengthened by CFRP has not been reported [9]. In fracture mechanics a crack is assumed to start when there is a notch or a stress concentration in the tension zone [10].

The first modelling based on the fracture mechanics theory in concrete material was presented by Hillerborg et al. [11]. It was demonstrated that there is a fracture zone ahead of the real crack that still has an ability to transfer stress. This fracture zone is known as fracture process zone (FPZ). The modelling of the FPZ in the beam- column joint is an important topic to predict crack propagation.

Many studied have been carried out on carbon fiber-reinforced polymer (CFRP) strengthened 
beam-column through experimental tests, numerical and an analytical methods with many types, shapes and angle of CFRP sheets, rods or plates under static and dynamic loading [12-17].

Parvin and Granata [18] modeled three beam-column joints by using various FRP laminates, wraps and various thicknesses to study their moment capacity. They showed that the selection of the FRP materials, wraps and thickness have effected the joint performance. Moment capacity has increased up to $37 \%$ compared to the original joints when the joints were strengthened with FRP laminates.

An experimental research was done to evaluate moment capacity of joint strengthened by using CFRP composite by Granata and Parvin [19]. Some strength systems by using FRP were tested to improve shear strength of the beam-column joint by Ghobarah and El-Amoury [20]. They showed which FRP system has enhanced the ductility, shear strength and moment capacity of the joint.

Also, Antonopoulos and Triantafillou [21] tested 18 joints strengthened with different configuration of CFRP strips and GFRP sheets to validate the theoretical method. They found out the effect of different parameters on the impressiveness of joint and GFRP. The axial load in column, reinforcement of the joint, CFRP versus GFRP and strips versus flexible sheets were the investigated variables. The failure modes were by composites debonding and ties rupture. The increase in column axial load, stiffness and the energy dissipation were $7 \%, 100 \%$ and $60 \%$, respectively.

They found better action of FRP sheets than strips, improving energy dissipation due to GFRP over CFRP, the helpful effect of added axial load of column on shear capacity, and increased impressiveness of the FRP because of less reinforcement in the joint. A numerical model was presented to study the effect of ply angle on the enhancement of shear capacity of the joint strengthened with CFRP by Parvin and Wu [22]. It showed that four covers of wrapping located at \pm 45 with regards to the horizontal directions were satisfactory for better shear capacity of the joint.

Experimental studies were done on existing jointed strengthened by CFRP for gravity load with no shear reinforcement within the joint core to improve the performance of such deficient joints by Parvin et al. [23]. Both design of CFRP, RC2U1 and RC3U3, significantly improved the joints performance and increased load capacity, displacement, dissipated energy, and stiffness as compared to control joints. However, the RC3U3 form is better than the RC2U1 sample because of higher number of CFRP applied.

Furthermore, FRP-strengthened beam-column joints have been studied experimentally [24-32]. However, limited models of crack propagation have been developed for FRP-strengthened beam-column joint under dynamic loading. Furthermore, a numerical model is known as a cost effective technique in comparison with experimental tests to predict the crack propagation and structural behavior of joint strengthened with CFRP. The proposed model is prepared to reduce cost of experimental test for CFRP-strengthened joints under dynamic load.

In studies that have previously been mentioned, experimental tests were done to calculate the moment capacity, shear capacity, effect of ply angle type. In these studies more, attention is given to configuration of FRP-strengthened joint behaviour than the location of cracks in joint. The effect of the FRP composites on the dynamic crack growth and strut zone has not been investigated yet in the joint strengthened with the FRP. In this paper, a numerical model is developed to use the fracture mechanics modelling for studying crack propagation in the FRP-strengthened joints under dynamic loads.

\section{Methodology and material}

A brief description of the finite element model is presented. A three-dimensional model is developed to predict the crack propagation under cyclic loading. The finite element model is implemented in ABAQUS software. In this study, the dynamic fracture analysis, which has been implemented by $\mathrm{Du}$ et al. [33], using the finite element method, is used to model the crack propagation in the concrete material. 
Since shear load is transferred through the concrete compression strut zone, it is, therefore, important to apply an accurate model for this zone (see Fig. 1). To model strut zone, the constitutive model presented by Mitra and Lowes [34] is used and is expressed as follows:

$\sigma_{c n}=f_{c_{\text {strut }}} \frac{w_{\text {strut }} \cos \alpha_{\text {strut }}}{w}$,

$\sigma_{c t}=f_{c_{-} \text {strut }} \frac{w_{\text {strut }} \sin \alpha_{\text {strut }}}{h}$,

where $\sigma_{c n}, \sigma_{c t}, f_{c_{s} s t r u t}, w_{\text {strut }}$ and $\alpha_{\text {strut }}$ are normal and shear stress of concrete in the panel component, strut stress, width of the strut and angle of inclination of the strut with the horizontal, respectively. The $w$ and $h$ are width and height of the joint, respectively (Fig. 1).

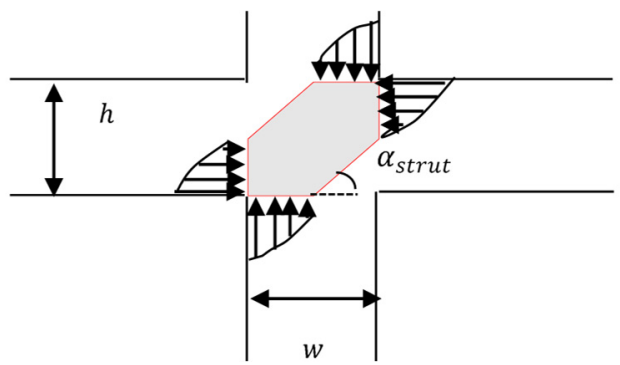

Fig. 1. Strut model

A composite model is required to simulate plane stress joint strengthened on the face of the strut zone. The equilibrium of stress on an element (Fig. 2) is defined by:

$\sigma_{x}=\sigma_{c n}+\rho_{F R P(x)} \cdot \sigma_{F R P(x)}$

$\sigma_{y}=\sigma_{c t}+\rho_{F R P(y)} \cdot \sigma_{F R P(y)}$

where $\sigma_{x}, \sigma_{y}, \rho_{F R P(x)}$ and $\rho_{F R P(y)}$ are the normal and shear stresses in the global coordinate system, FRP reinforcement ratios in the global $x$ and $y$ directions, respectively. $\sigma_{F R P(x)}$ and $\sigma_{F R P(y)}$ stresses in the $x$ and $y$-FRP reinforcement, respectively.

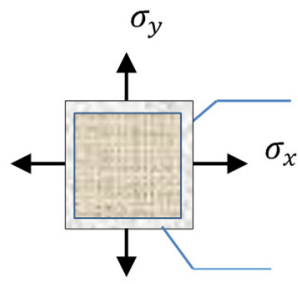

Concrete
FRP

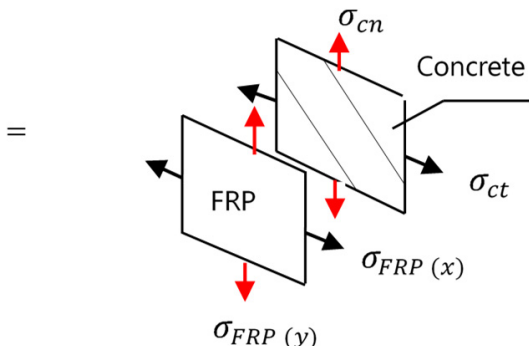

$\sigma_{F R P}(y)$

Fig. 2. Applied stresses

Ultimate force of beam-column joint is used which has been implemented using the finite element method by Borghini et al. [35] to control collapse. Tension stress and compression stress are [35]:

$\sigma_{\text {coll-cn }}=\frac{N}{2 A_{g}}+\sqrt{\left(\frac{N}{2 A_{g}}\right)^{2}+\left(\frac{V}{A_{g}}\right)^{2}}$, 
$\sigma_{\text {coll-ct }}=\left|\frac{N}{2 A_{g}}-\sqrt{\left(\frac{N}{2 A_{g}}\right)^{2}+\left(\frac{V}{A_{g}}\right)^{2}}\right|$,

where are $N, A_{g}$ and $V$ the axial force acting on the upper column, the gross area of the column, the horizontal shear acting in the joint panel, respectively. $V$ is evaluated based on both the column shear and the shear transmitted by the beam reinforcing bars. When joint is collapsed, $\sigma_{c n}$ is replaced with $\sigma_{c o l l-c n}$ and $\sigma_{c t}$ is replaced with $\sigma_{\text {coll-ct }}$ in Eqs. (3) and (4), respectively. The C3D8 Bricks are used to model the concrete. The FRPs are modeled by using the S4 shell in ABAQUS software. The FRPs behaviors are elastic. The crack initiates from the surface and then is propagated in the concrete material. In the proposed model, the two parameter fracture model [4] is used to predict the initial crack. The model is used by Bruno et al. [36] to predict dynamic debonding in FRP strengthened with the fracture mechanics approach. The nonlinearity is used in the interface element to simulate debonding of the FRP-concrete (Fig. 3). The steel reinforcements were modeled using truss elements. The steel reinforcement was assumed to be elastic-perfectly plastic.

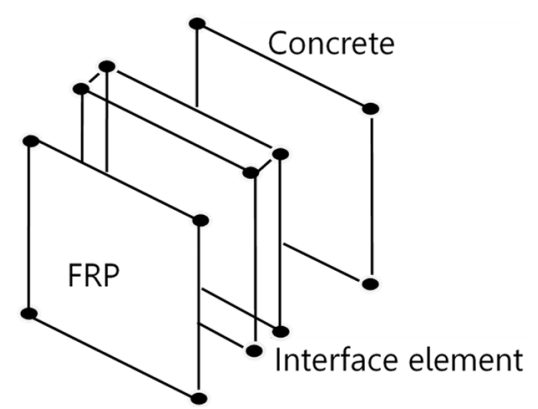

Fig. 3. Interface element for modeling bond slip of FRP

A spring is proposed to be placed between nodes to model crack formation at the initial stage. As used in the Jenq-Shah's theory [37], the crack starts when the principal stress in the node reaches the tensile stress of the concrete material. If the crack mouth opening reaches the critical value, then spring stiffness is equal to zero and the element is removed. The single-active-crack mode is used to model multiple-cracks as presented by Shi et al. [38].

\section{Results and discussion}

A CFRP-wrapped beam-column joint under combined axial and cyclic loadings, which was previously reported in the literature [22], was used to validate the accuracy of the proposed model. The CFRP-wrapped beam-column was tested by Gergely et al. [39] Fig. 4 illustrates an initial finite element mesh modeled for the beam-column joint.

The thickness of CFRP is $0.71 \mathrm{~mm}$ (Fig. 5). The cyclic lateral load in the global $X$ direction is applied at the outer side of the column. The axial load was applied at the top of the column $(111 \mathrm{kN})$. The joint was modeled by ABAQUS software with 8896 (average size was $14 \mathrm{~mm} \times 14 \mathrm{~mm} \times 10 \mathrm{~mm}$ ) elements. Fig. 6 shows reinforcement detail of beam-column joint by ABAQUS software.

Fig. 7 shows correspondence between the results of the study by Parvin and $\mathrm{Wu}$ [22] and those obtained by the proposed model for load-displacement of the control joint. The proposed numerical results are consistent (2\% to $7 \%$ difference) with the work presented by Parvin and $\mathrm{Wu}$ [22]. The failure load $(42.7 \mathrm{kN})$ had $5.4 \%$ difference compared with the failure load of study by Parvin and $\mathrm{Wu}$ [22]. Based on the proposed model, the maximum lateral displacement in push and pull paths for the control join are 9.9 and mm 12.8, respectively. In Comparison with the study 
by Parvin and $\mathrm{Wu}$ [17], the maximum lateral displacement in push path is $10.4 \mathrm{~mm}$ and in pull path is $13.0 \mathrm{~mm}$. Based on the proposed model, the maximum load capacities of the control joint in push load is 42.7 and in pull load is $41.4 \mathrm{kN}$.

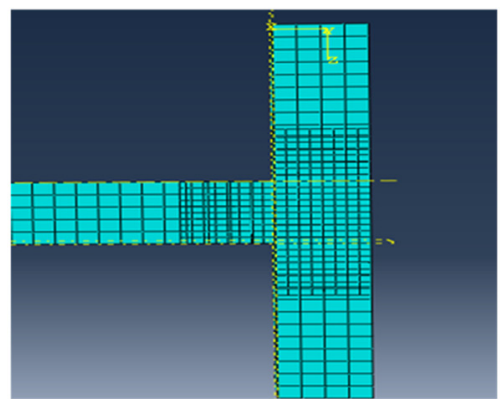

Fig. 4. Initial finite element mesh modeled by ABAQUS software

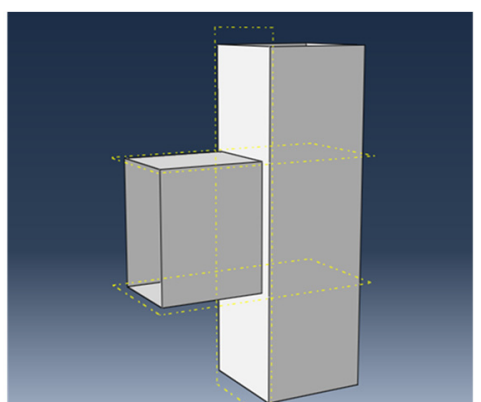

Fig. 5. CFRP-wrapped modeled by ABAQUS software

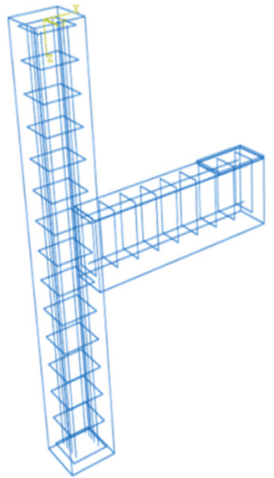

Fig. 6. Reinforcement detail of beam-column joint by ABAQUS software

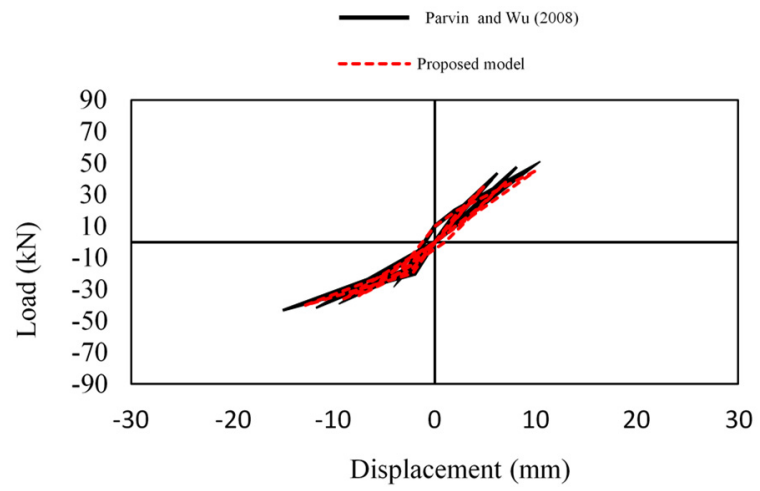

Fig. 7. Load vs. displacement for control beam-column joint

Load versus displacement by the present model was compared to a study by Parvin and Wu [22] in Fig. 7. As seen in Fig. 7, the results of the present model showed good agreement with the study by Parvin and $\mathrm{Wu}[22]$ results (7.1-11.6 \%). As shown in the hysteresis loop of Fig. 7 the results of using the proposed model, the maximum push and pull loads are $81.23 \mathrm{kN}$, and $80.03 \mathrm{kN}$ and the maximum displacements in pull and push are $19.22 \mathrm{~mm}$ and $20.15 \mathrm{~mm}$, respectively. Comparing with results of the study presented by Parvin and $\mathrm{Wu}$ [22], the maximum displacements in pull and push loads have approximately $6.7 \%$ and $5 \%$ difference, respectively. Comparing with the control joint in Fig. 7, load capacity has increased by $51 \%$. Based on the 
present investigation, the maximum displacement in the joint strengthened with the CFRP sheet is $64.3 \%$ larger compared with the control joint.

Fig. 9 illustrates the crack propagation pattern in the beam-column joint without FRP (control joint) at the failure load $(39.7 \mathrm{kN})$. The fracture zones are shown in green color, while the real cracks are displayed in red color. Using the proposed model, the maximum displacement is $10.93 \mathrm{~mm}$. furthermore and based on the results of the study by Parvin and $\mathrm{Wu}$ [22], this value is $10.4 \mathrm{~mm}$. The length and width of shear crack in the joint core region are $106 \mathrm{~mm}$ and $1.9 \mathrm{~mm}$, respectively. This crack is causing the shear failure mechanism. The tensile damage is defined from 0 to 1 in the ABAQUS software. The results showed that the maximum value of the damage parameter is $+1.00 \geq 0.1$. Therefore, the tensile damage occurred along the red lines as shown in Fig. 9. It should be noted that the crack path is smooth, although in this study the crack path is illustrated by unconventional lines.

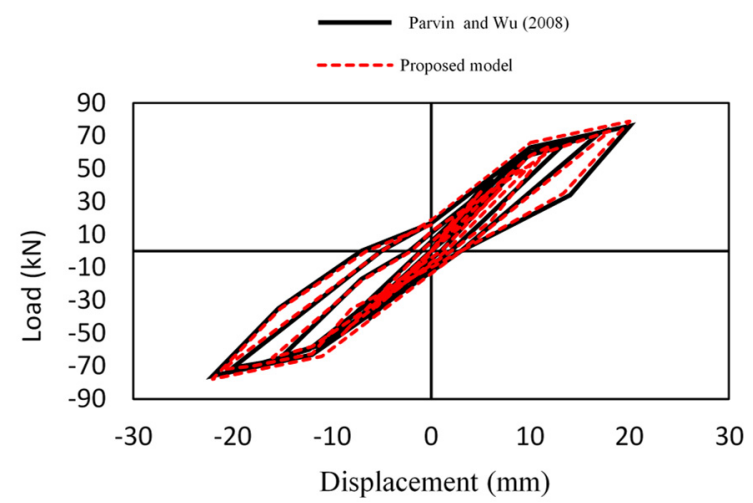

Fig. 8. Load vs. displacement for beam-column joint CFRP wrap

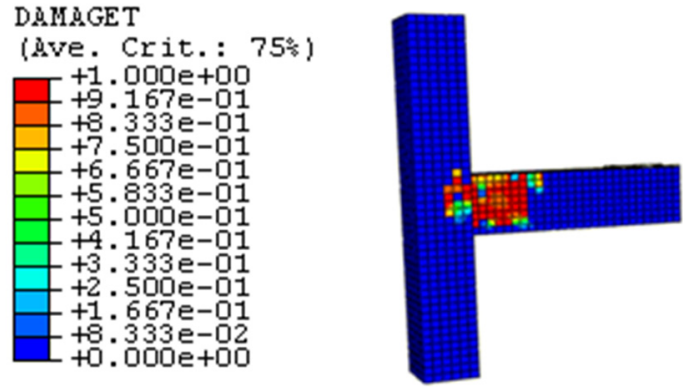

Fig. 9. Cracks path of the control joint

Fig. 10 shows the stress versus strain curve of the biggest crack at the top intersection of the beam and column in the control joint. The envelope of the loops is shown in the black line and the loops are represented in red lines. The decrease of peak loads at the first and second loading cycles would be caused by the softening of joint. At the last loading cycles, cracks are propagated rapidly. As shown in Fig. 10, the stress-strain softening behavior of the crack represents that crack propagation occurs in concrete material. As shown in Fig. 10, the push and pull load paths are initially different and then these paths coincide.

Fig. 11 shows the crack propagation pattern in the beam-column joint with FRP that obtained by the present study. The real cracks are shown in red color. Five flexure cracks were observed in the beam and shear crack in the joint core region in the control joint (see Fig. 9). However, no considerable flexural cracks are observed in the strengthened joint core region (Fig. 11). Only small cracks are initiated in beam close to the strengthened area.

As shown in Fig. 11, the tensile damage occurred along the red lines in the beam. The shear 
cracks are formed at the control joint, but did not appear in the strengthened joint. The CFRP sheet helped delaying the propagation of shear and flexural cracks. Crack propagation was managed with the CFRP sheet. By using the CFRP sheet in the beam-column joint, the length of cracks is decreased. The use of CFRP prevented cracks and maintained the original shape of beam-column joint and increased deformability.

The beam-column joint without FRP (control joint) is characterized by the presence of a compression strut zone (Fig. 12) at $30.0 \mathrm{kN}$ load. The compressive stress legend is presented on the left side of Fig. 12. The compressive stress is distributed uniformly on the strut width.

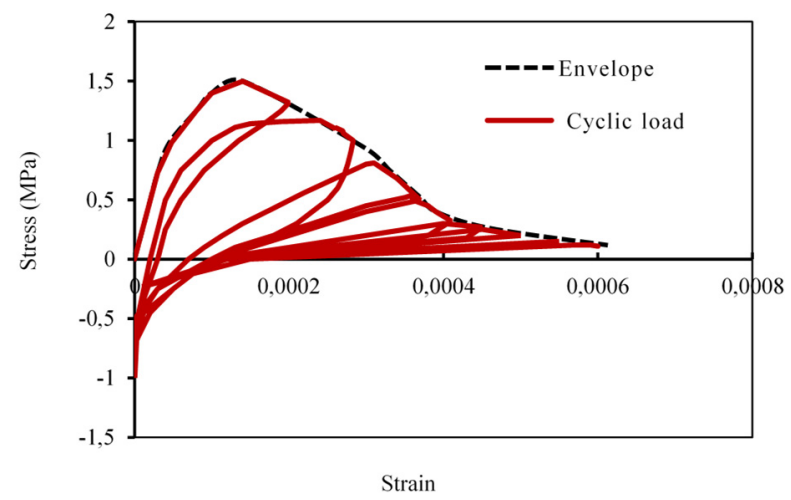

Fig. 10. Stress versus strain responses hysteresis in the control joint

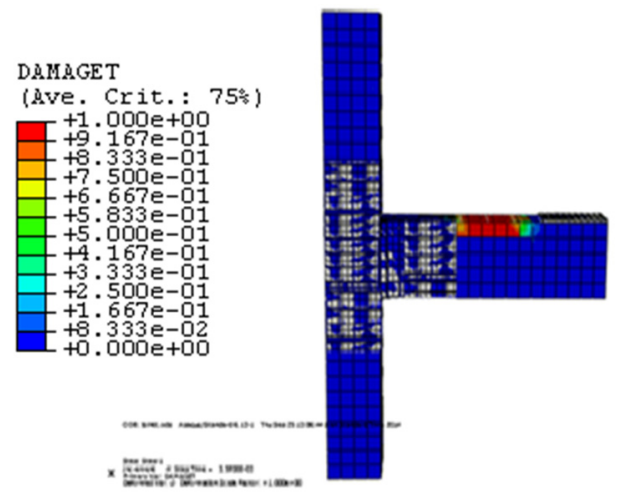

Fig. 11. Cracks path of the beam-column joint with FRP
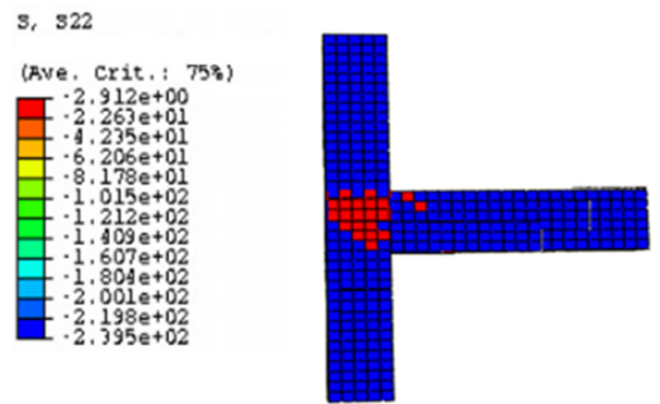

Fig. 12. Compression strut zone in the beam-column joint without CFRP

Fig. 13 shows the effect of CFRP-strengthened on strut width. For comparing with the control joint, Fig. 13 illustrates the compressive stress in the joint strengthened by CFRP at $30 \mathrm{kN}$ lateral load. As illustrated in Fig. 13, compressive stress can be observed at joint core and the bottom 
of the beam. In the beam-column joint with CFRP (Fig. 13), the strut width is greater. Therefore, it is observed that the width of strut zone in the joint increases with the application of FRP strengthening.
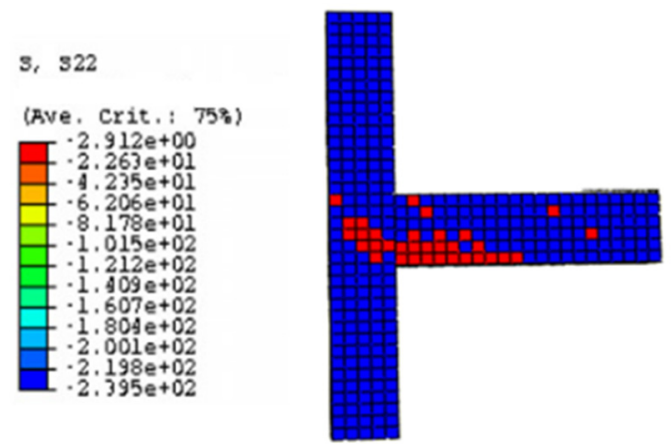

Fig. 13. Compression strut zone in the FRP-strengthened joint

\section{Conclusions}

A numerical model was developed to predict crack propagation of CFRP-strengthened joints under dynamic loading. The crack patterns were estimated according to the proposed fracture model for the CFRP-strengthened joins. A three-dimensional finite element model was then developed to analyze the crack propagation under cyclic loading in the ABAQUS software. In this study, dynamic fracture analysis was used to model the crack propagation in concrete. Also, the model was used to predict dynamic debonding in the CFRP. The results of the present study showed good agreement with available experimental results by $7.1 \%$ to $11.6 \%$ difference. The model shows that the crack propagation would be limited by using CFRP composites in the beam-column joint area. It can be observed that the number, pattern and length of cracks are changed by using FRP composites in the joint area. Furthermore, it is observed that the width of the strut zone in the joint increases with the application of the CFRP.

\section{References}

[1] Deaton J. B. Nonlinear Finite Element Analysis of Reinforced Concrete Exterior Beam-Column Joints with Nonseismic Detailing. Thesis, School of Civil and Environmental Engineering Georgia, Institute of Technology, 2013.

[2] Tryding J., Ristinmaa, M. Normalization of cohesive laws for quasi-brittle materials. Engineering Fracture Mechanics, Vol. 178, 2017, p. 333-345.

[3] Said A. M., Nehdi M. L. Use of FRP for RC frames in seismic zones: Part I. Evaluation of FRP beamcolumn joint rehabilitation techniques. Applied Composite Materials, Vol. 11, Issue 4, 2004, p. 205-226.

[4] Shahbazpanahi S., Abang A. A. A., Kamgar A., Farzadnia N. Fracture mechanic modeling of fiber reinforced polymer shear-strengthened reinforced concrete beam. Composites Part B: Engineering, Vol. 68, 2014, p. 113-120.

[5] Dong W., Yang D., Kastiukas G., Zhang B. Experimental and numerical investigations on fracture process zone of rock-concrete interface. Fatigue and Fracture of Engineering Materials and Structures, Vol. 40, Issue 5, 2017, p. 820-835.

[6] Baji H., Eslami A., Ronagh H. R. Development of a nonlinear FE modelling approach for FRPstrengthened RC beam-column connections. Structures, Vol. 3, 2015, p. 272-285.

[7] Shahbazpanahi S., Ali A. A. A., Aznieta F. N., Kamgar A., Farzadnia N. A simple and practical model for FRP-reinforced cracked beam. European Journal of Environmental and Civil Engineering, Vol. 18, Issue 3, 2013, p. 293-306.

[8] Shahbazpanahi S., Kamgar A. A novel numerical model of debonding of FRP-plated concrete beam. Journal of the Chinese Institute of Engineers, Vol. 38, Issue 1, 2014, p. 24-32. 
[9] Kiran R., Genesio G. A case study on pre 1970s constructed concrete exterior beam-column joints. Case Studies in Structural Engineering, Vol. 1, 2014, p. 20-25.

[10] Shahbazpanahi S., Ali A. A. A., Aznieta F. N., Kamgar A., Farzadnia N. Modelling of the fracture process zone to improve the crack propagation criterion in concrete. Journal of the South African Institution of Civil Engineering, Vol. 55, Issue 3, 2013, p. 2-9.

[11] Hillerborg A., Modeer M., Petersson P. E. Analysis of crack formation and crack growth in concrete by means of mechanics and finite element. Cement and Concrete Research, Vol. 6, 1976, p. 773-782.

[12] Ghobarah A., Said A. Shear strengthening of beam-column joints. Engineering Structures, Vol. 24, Issue 7, 2002, p. 881-888.

[13] Karayannis C. G., Sirkelis G. M. Effectiveness of RC beam-column connections strengthening using carbon-FRP jackets. Proceedings of the 12th European Conference on Earthquake Engineering, London, 2002.

[14] Clyde C., Pantelides C. P. Seismic evaluation and rehabilitation of R/C exterior building joints. In Proceedings of the 7th U.S. National Conference on Earthquake Engineering, Boston, 2002.

[15] Mukherjee A., Joshi M. FRPC reinforced concrete beam-column joints under cyclic excitation. Journal of Composite Structures, Vol. 70, Issue 2, 2004, p. 185-199.

[16] Haach V., Debs E., Debs M. Evaluation of the influence of the column axial load on the behavior of monotonically loaded R/C exterior beam-column joints through numerical simulations. Engineering Structures, Vol. 30, Issue 4, 2008, p. 965-975.

[17] Kaliluthin A., Kothandaraman S. Experimental investigation on behavior of reinforced concrete beam column. International Journal of Civil and Structural Engineering, Vol. 4, Issue 3, 2014, p. 248-261.

[18] Parvin A., Granata P. J. Investigation on the effects of fiber composites at concrete joints. Composites Part B: Engineering, Vol. 3, Issue 6, 2000, p. 499-509.

[19] Granata P. J., Parvin A. An experimental study on Kevlar strengthening of beam-column connections. Composite Structures, Vol. 53, Vol. 2, 2001, p. 163-171.

[20] Ghobarah A., El-Amoury T. Seismic rehabilitation of deficient exterior concrete frame joints. Journal of Composites for Construction, Vol. 9, Issue 5, 2005, p. 408-416.

[21] Antonopoulos C. P., Triantafillou T. C. Experimental investigation of FRP-strengthened RC beamcolumn joints. Journal of Composites for Construction, Vol. 7, Issue 1, 2003, p. 39-49.

[22] Parvin A., Wu S. Ply angle effect on fiber composite wrapped reinforced concrete beam-column connections under combined-axial and cyclic loads. Composite Structures, Vol. 82, Issue 4, 2008, p. $532-538$.

[23] Parvin A., Altay S., Yalcin C., Kaya O. CFRP rehabilitation of concrete frame joints with inadequate shear and anchorage details. Journal of Composites for Construction, Vol. 14, Issue 1, 2010, p. 72-82.

[24] Di Ludovico M., Lignola G. P., Prota A., Cosenza E. Nonlinear analysis of cross sections under axial load and biaxial bending. ACI Structural Journal, Vol. 107, Issue 4, 2010, p. 390-399.

[25] Akguzel U., Pampanin S. Assessment and design procedure for the seismic retrofit of reinforced concrete beam-column joints using FRP composite materials. Journal of Composites for Construction, Vol. 16, Issue 1, 2012, p. 21-34.

[26] Park S., Mosalam K. M. Parameters for shear strength prediction of exterior beam-column joints without transverse reinforcement. Engineering Structures, Vol. 36, 2012, p. 198-209.

[27] Hadi M. N. S., Pham T. M., Lei X. New method of strengthening reinforced concrete square columns by circularizing and wrapping with fiber-reinforced polymer or steel straps. Journal of Composites for Construction, Vol. 17, Issue 2, 2013, p. 229-238.

[28] Singh V., Bansal P. P., Kumar M., Kaushik S. K. Experimental studies on strength and ductility of CFRP jacketed reinforced concrete beam-column joints. Construction and Building Materials, Vol. 55, 2014, p. 194-201.

[29] Realfonzo R., Napoli A., Pinilla J. G. R. Cyclic behavior of RC beam-column joints strengthened with FRP systems. Construction and Building Materials, Vol. 54, 2014, p. 282-297.

[30] Del Vecchio C., Di Ludovico M., Balsamo A., Prota A., Manfredi G., Dolce M. Experimental investigation of exterior RC beam-column joints retrofitted with FRP systems. Journal of Composites for Construction, Vol. 18, Issue 4, 2014, p. 1-9.

[31] Kaliluthin A. K., Kothandaraman S., Aha T. S. A review on behavior of reinforced concrete beam column joint. International Journal of Innovative Research in Science, Engineering and Technology, Vol. 3, Issue 4, 2014, p. 11299-11312. 
[32] Kulkarni S. M., Patil Y. A novel reinforcement pattern for exterior reinforced concrete beam column joint. Procedia Engineering, Vol. 51, 2014, p. 184-193.

[33] Du J., Kobayashi A. S., Hawkins N. M. FEM dynamic fracture analysis of concrete beams. Journal of Engineering Mechanics, Vol. 115, Issue 10, 1989, p. 2136-2149.

[34] Mitra N., Lowes L. N. Evaluation, calibration, and verification of a reinforced concrete beam-column joint model. Journal of Structural Engineering, Vol. 133, Issue 1, 2007, p. 105-120.

[35] Borghini A., Gusella F., Vignoli A. Seismic vulnerability of existing R.C. buildings: A simplified numerical model to analyse the influence of the beam-column joints collapse. Engineering Structures, Vol. 121, 2016, p. 19-29.

[36] Bruno D., Greco F., Lonetti P. A fracture-ALE formulation to predict dynamic debonding in FRP strengthened concrete beams. Composites Part B: Engineering, Vol. 46, 2013, p. 46-60.

[37] Jenq Y. S., Shah S. P. A two parameter fracture model for concrete. Journal of Engineering Mechanics, Vol. 111, Issue 4, 1985, p. 1227-1241.

[38] Shi Z., Ohtsu M., Suzuki M., Hibino Y. Numerical analysis of multiple cracks in concrete using the discrete approach. Journal of Structural Engineering, Vol. 127, Issue 9, 2001, p. 1085-1091.

[39] Gergely J., Pantelides C. P., Reaveley L. D. Shear strengthening of RCT joint using CFRP composites. Journal of Composites for Construction, Vol. 4, Issue 2, 2000, p. 56-64.

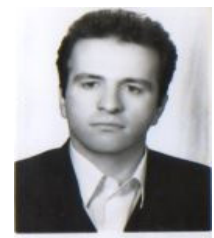

Shahriar Shahbazpanahi was born in Sanandaj, Iran on 14/2/1972. He obtained his Bachlor Degree in civil engineering from Islamic Azad University of Sanandaj, Iran during 1991-1995. He did his Master's in structural engineering from Bahonar university Kerman in 1999. He did as lecturer in Islamic Azad University of Sanandaj, Iran during 1999-2007. He did his Ph.D. in structural engineering in 2007. Now, he is an Assistant Professor in Islamic Azad University of Sanandaj. 